\title{
Developing Program Standards for Adult ESL
}

Clare Myers

The following article is a summary of the process undertaken by the Alberta Teachers of English as a Second Language (ATESL) in developing standards for adult ESL programs across the province. It outlines the various stages involved in this government-funded project, highlights the outcomes and learnings from each stage, and raises some questions related to the future implementation of program standards.

\section{Introduction}

Given the current economic and political climate, it is not surprising that the words quality, accountability, and standards have become central to the discussion of adult ESL education. The demand by public funders for evidence of program quality, cost effectiveness, and accountability has given urgency and impetus to the task of developing program standards. However, it is not only funders who have a vested interest in promoting quality and accountability in adult ESL programs. All of us involved in ESL education (learners, teachers, administrators, and community stakeholders) stand to benefit from the development of standards that will deepen our understanding of what constitutes quality in ESL programming and strengthen our efforts to achieve the best programming possible.

The following article is a summary of the process undertaken by the Alberta Teachers of English as a Second Language (ATESL) in developing standards for adult ESL programs across the province. In many ways, what began as a well-defined government project to establish program standards evolved over a period of a year and a half into an interesting and challenging learning journey for ATESL, which entailed venturing into uncharted territory, questioning previously held assumptions, and managing a diversity of perspectives. The stages of that journey are recounted here as a resource and a guide to other affiliates who may be thinking of mapping a similar course.

\section{Charting New Territory. Background to the ATESL Program}

Standards Project

In 1996 the Government of Alberta (Advanced Education and Career Development, 1996) contracted ATESL to develop program standards for adult ESL programs in the province. At that time there were no commonly agreed- 
upon standards for discussing or determining the quality of ESL programs for adult learners in Alberta. Although the Best Practice Guidelines, prepared by ATESL in 1995, describes aspects of quality in ESL programming, this document was intended to guide programs in a voluntary process of selfstudy and review. There was a need, therefore, to establish explicit and consistent program standards that would serve as a criterion "yardstick" against which ESL funders, clients, and service providers could evaluate program quality.

\section{Forming a Crew}

In September 1996, an ATESL advisory committee consisting of a cross-section of ESL professionals and a government representative was established to oversee the development of the standards project. The committee hired a principal researcher who became responsible for the facilitation of the process and for the development and writing of the program standards document.

\section{Stage 1. Scanning the Horizon: Literature Review (September-December 1996)}

The first step in developing standards for adult ESL programs in Alberta was to undertake an extensive literature review of current program standard schemes, both national and international. The standards reviewed included international accreditation schemes (British Council, 1996; National ELICOS, 1995); standards developed by professional organizations (American Association of Intensive English Programs [AAIEP], 1996; TESOL, 1995, 1997); government initiatives (California Department of Education, 1992, 1994); adult literacy standards schemes (Literacy Ontario, 1995); and best practice guidelines (ATESL 1995; Selman, 1991). A report based on this review, entitled An Overview of Program Standards for Adult English as a Second Language (ATESL, 1996), was completed in December 1996. In addition to outlining various standard schemes, the report drew on the work of Clymer-Spradling (1993), Mansoor (1992), Wrigley and Ewen (1995), Wrigley and Guth (1992), and Wrigley, Spruck, et al. (1993) in discussing some of the key issues related to the development and implementation of ESL standards. The report recommended that core quality standards for adult ESL programs in Alberta:

- be baseline and flexible in nature, allowing for the diversity of ESL delivery, funding, and program contexts;

- emphasize processes that ensure quality rather than focusing on narrow outcomes or products;

- be tied to a system of monitoring and compliance (e.g., certification); and

- be developed through a consultative process involving all ESL stakeholders across the province. 


\section{Stage 2. Shaping a Course: The Best Practice Guidelines (January-March 1997)}

One of the recommendations of the research report was that ATESL return to an earlier document, Best Practice Guidelines (ATESL, 1995), and use this as a starting framework for developing program standards. Although the Best Practice Guidelines was intended to be used as a tool for program self-study rather than a set of minimal standards, it does provide a helpful description of what constitutes quality in adult ESL programming and instruction. Taking this description as their starting point, a representative group of ESL program administrators participated in a working session aimed at articulating the standard implicit in each guideline, identifying the features of that standard (how it is present in a program), and specifying evidence (in the form of documentation or processes) that would demonstrate the standard was being met. The outcome of this working session was the Preliminary Draft of Program Standards, a document that was essentially a series of checklists addressing eight areas of program delivery: program philosophy, curriculum, staffing, working conditions, learner support, learner achievement, program administration, and program evaluation. Each checklist contained a general standard statement followed by a description of the features of that standard and a list of suggested indicators or evidence.

The Preliminary Draft was sent to all those who had participated in the working session for comment and review. The feedback obtained through this review was interesting and unexpected. Many reviewers indicated that although the document described important characteristics of quality from an administrative and instructional perspective, the checklists failed to adequately capture the "heart" or the "essence" of quality in ESL programming. There was a sense that something was lacking in the checklists and that there was need to explore the nature of quality in a deeper, more holistic way. As a result of this feedback, a decision was made to set aside the Preliminary Draft and seek a broader understanding of quality in adult ESL through the input of regional focus groups.

\section{Stage 3. Changing Tack: Focus Group Sessions (April-June 1997)}

A total of 10 focus group sessions were conducted in three regional centers (Calgary, Edmonton, and Grande Prairie) over a period of three months. These included four learner groups, three teacher groups, one settlement worker group, an ESL/LINC administrator group, and the ATESL Board. Participants in each group were invited to share their perceptions and experiences of quality by responding to the questions: "What is the essence of 'quality' in adult ESL programming? How do we know a 'quality' program from a mediocre or poor program?" 
The insights and experiences of focus group participants added a new dimension to the understanding of quality in adult ESL. When asked to describe the essence of quality, participants tended not to talk in terms of specific administrative and instructional practices. Instead, they spoke about the fundamental philosophical principles on which quality programs are built: principles such as integrity, collaboration, participation, accountability, and responsiveness. They spoke to the ways these principles become embodied in good program practices and are lived in the relationships among the various stakeholders (administrators, support staff, teachers, and learners) involved with a program. They suggested that when program practices and interpersonal relationships are congruent with principles such as trust, respect, open communication, valuing, sensitivity, and professionalism, there is a kind of spirit that pervades all aspects of the program. This spirit is the hallmark of quality.

What emerged through focus group discussions was an image of an ESL program as a dynamic and evolving system. The components of this system (guiding principles, program practices, and a community of people) do not exist in isolation, but interact in fluid and organic ways to create the synergy of the whole. To understand the essence of quality in the whole of an ESL system, then, is to understand that quality is not ascertained by examining its manifestation in only one part of that system (i.e., program practices). It is the interconnectedness of the different parts of the system, the weaving together of administrative practices with guiding principles and caring relationships that creates the dynamic we call quality.

\section{Stage 4. Plotting a New Course: Draft Program Standards for Adult ESL (September-November 1997)}

The challenge facing the ATESL standards committee at this point was how to integrate the holistic view of quality arrived at through focus groups with the good practice checklists contained in the preliminary draft of program standards. It was clear that these checklists emphasized practices in isolation from the principles underlying them and the voices of people (learners, teachers, administrators, etc.) involved with them. It was decided that the revised draft of program standards should include an intentions section that would stand alongside each standard statement and the list of suggested evidence. This intentions section would make explicit the link between the standard and the principles underlying it and, where appropriate, reflect the comments, concerns, and experiences of people involved in the focus groups. In seeking to illuminate the connection between program practices, principles, and people, the standards document would reflect a more holistic, less administrative notion of quality in adult ESL programming.

Drawing on the standard schemes reviewed in the literature, the checklists from the Best Practice Guidelines, and the input of focus groups, a revised 
draft of the standards document was now developed. This document contained a set of minimal standards for seven areas of programming: program purpose, curriculum and instruction, staffing, administration, facilities, equipment and resources, learner support, and learner achievement. Each standard statement was followed by a description of the intention of that standard and a list of sample indicators or evidence that programs might provide. Table 1 gives an example of this format, a set of sample standards for curriculum and instruction.

\section{Stage 5. Testing the Waters: Field Review (November 1997-January 1998)}

Once the draft of the program standards document was completed, it was necessary to elicit critical feedback on the applicability of the standards across a wide range of ESL delivery contexts. One of ATESL's concerns was that the standard statements be broad enough to capture the elements of quality essential to all programs, regardless of context, and that the suggested list of indicators for each standard be flexible enough to allow for program variation.

Nine programs representing a variety of delivery contexts (settlement, agencies, public institutions, and private providers) as well as a diversity of program types (English for Settlement, English for Academic Purposes, English for the Workplace, Continuing Education, and international schools) participated in a field review of the draft standards document. Programs were asked to work through the document, identify its strengths and shortcomings, and make specific recommendations for change. On receipt of each program's feedback, a meeting was held (in person or by telephone) to discuss the review process and to clarify areas of concern and recommendations.

\section{Setting Sail}

Feedback from the field review was comprehensive and generally positive. Although there was some disagreement on the wording, interpretation, and indicators of specific standards, there was overall acknowledgment that the document described essential and common elements of quality in ESL programming. On the basis of feedback obtained through the review, changes to the structure and content of the document were made. The revised draft was sent out to participating programs for further comment, and following this the Program Standards For Adult ESL (Working Document) was compiled.

\section{Stage 6. At the Helm: ATESL Guiding Principles for}

Implementation of Program Standards (March 1998)

Although the field review indicated widespread recognition of the need for program standards, there remained a great deal of anxiety and concern 

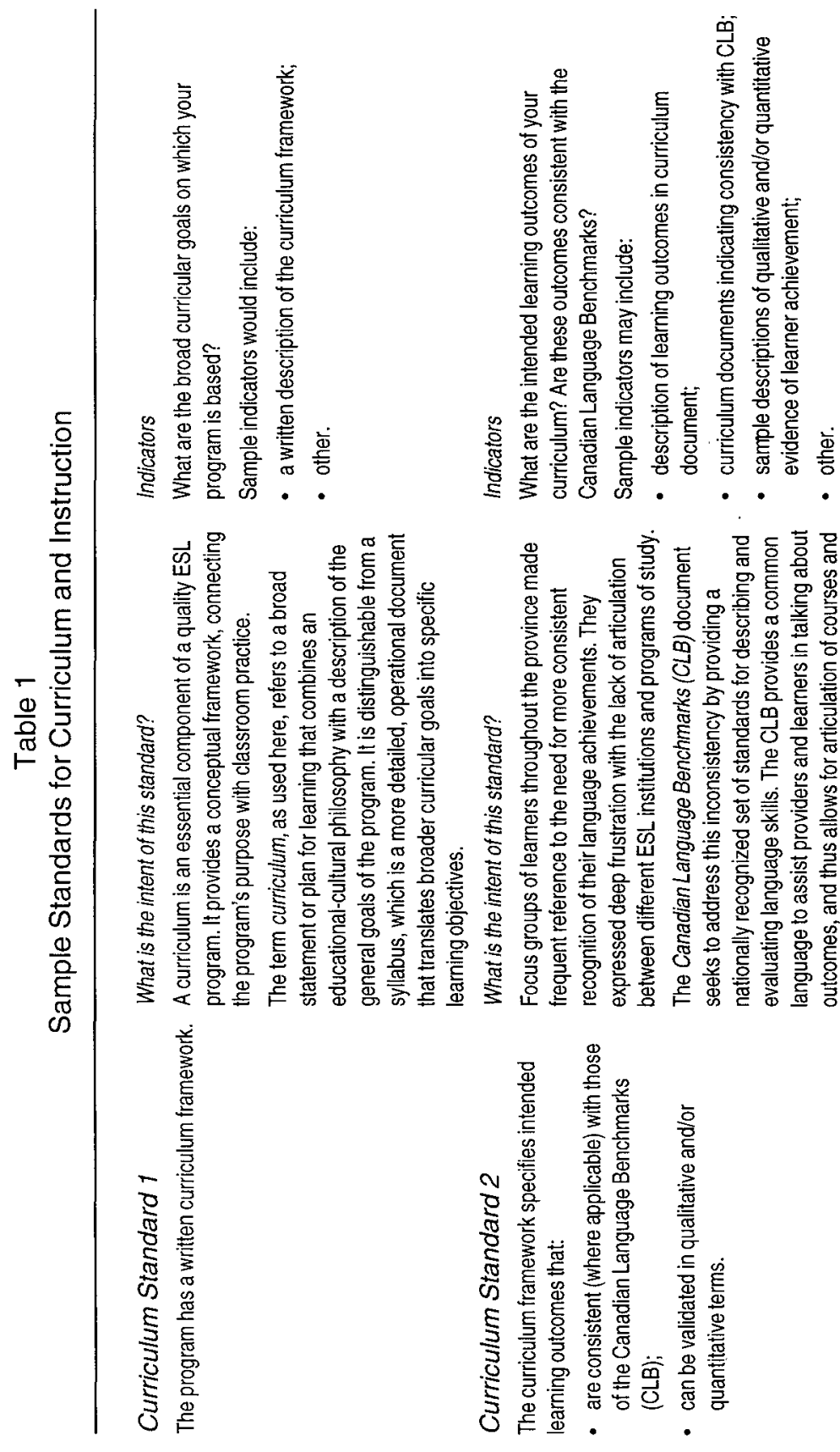

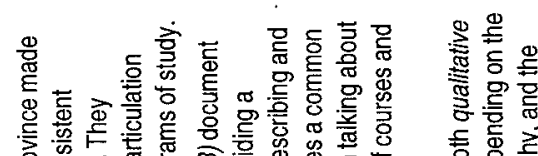

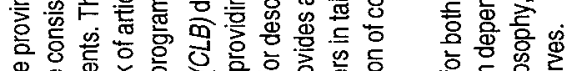
吾品 今.

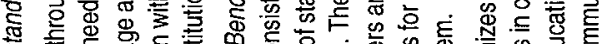
क क क 象 政密

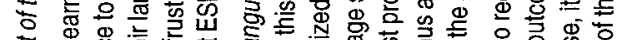

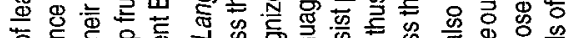
엥

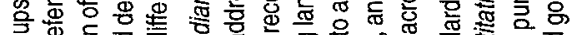

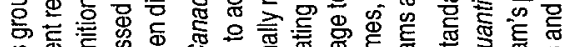
क

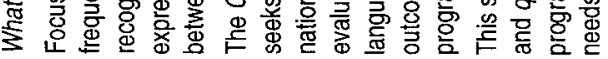

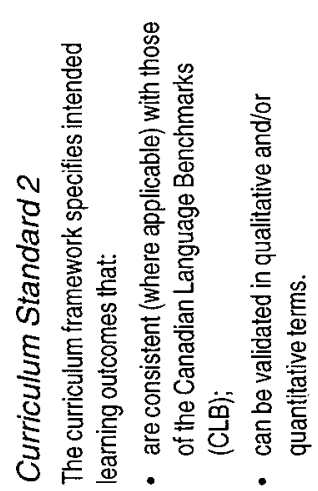



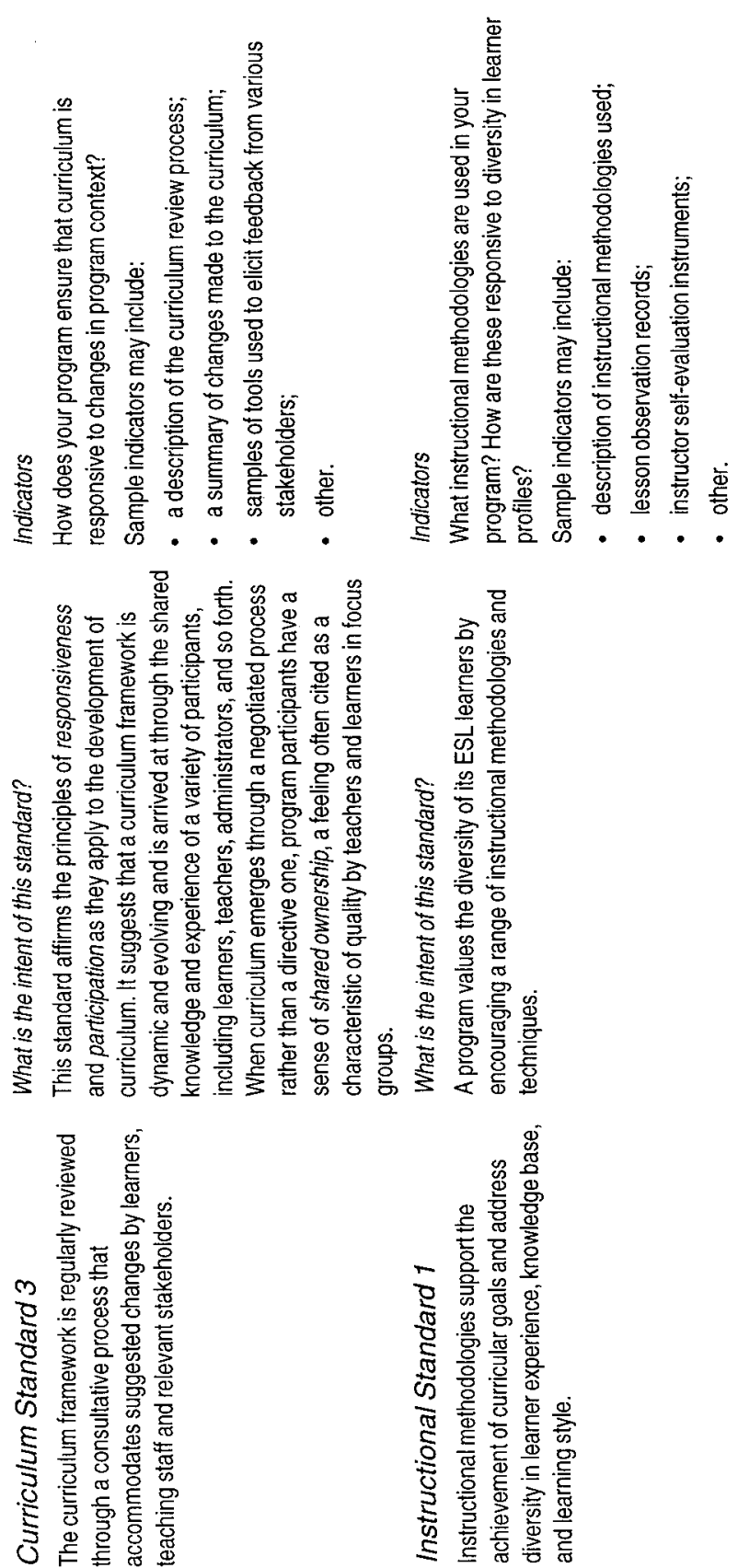
regarding issues of implementation. Underlying these concerns is the realization that tremendous diversity exists in the resource base of ESL programs in Alberta, with some programs operating on severely reduced budgets. It would be difficult and unrealistic, therefore, to compare programs and hold them accountable to an external set of outcome standards without consideration of financial, human, and resource constraints.

In order to give voice to these concerns and to influence and guide the government's future decisions regarding implementation, ATESL invited program administrators from across the province to meet and formulate specific recommendations for an implementation process. As a result of this meeting, a paper entitled Guiding Principles for Implementation of the ESL Program Standards was drawn up and incorporated into the program standards working document. The guiding principles speak to the need for adequate funding, sufficient time, and available resources to support those programs that are not currently meeting some standards in their operation. They also include specific recommendations and strategies for piloting, revising, monitoring, and reviewing the standards and the implementation process.

\section{Stage 7. Navigating a New Passage: Future Directions}

ATESL now has a working document that outlines minimal standards of quality for adult ESL programs in the province. This document currently rests with the Alberta government for review and ratification. Although government funders will ultimately determine how the document is used and implemented, ATESL will remain "on board," helping to steer a course that will ensure program standards are implemented through pathways that are open, inclusive, and responsive to changing contexts.

\section{Acknowledgments}

I would like to thank Marian Rossiter for her helpful feedback on an earlier draft of this article. My thanks and appreciation to all the members of the ATESL Program Standards Advisory Committee for their commitment, ideas, and support.

\section{The Author}

Clare Myers is an adult educator and ESL instructor. She currently teaches with the Calgary Board of Education and the University of Calgary. Clare was the principal researcher and developer of the ATESL program standards project.

\section{References}

Alberta Teachers of English as a Second Language (ATESL). (1995). Best practice guidelines for adult ESL/LINC programming and instruction in Alberta. Edmonton, $\mathrm{AB}$ : Author.

Alberta Teachers of English as a Second Language (ATESL). (1996). An overview of program standards for adult English as a Second Language. Edmonton, AB: Author.

American Association of Intensive English Programs (AAIEP). (1996). Promotional literature. Available: http://www.outfitters.com/com/aaiep. 
British Council. (1996). English in Britain accreditation scheme (promotional literature). Manchester, UK: Author.

California Department of Education. (1992). English as a second language model standards for adult education programs. Sacramento, CA: Bureau of Publications.

California Department of Education. (1994). English as a second language quality indicators for adult education programs. Sacramento, CA: Bureau of Publications.

Clymer-Spradling, C. (1993). Quality, standards and accountability in ESL programs. Washington, DC: Southport Institute for Policy Analysis. (ERIC Document Reproduction Service No. ED 384 255)

Literacy Ontario. (1995). Quality standards for adult literacy: A practitioner's guide to the accountability framework for the adult literacy education system and core quality standards for programs. Toronto, ON: Literacy and Basic Skills Section, Ontario Training and Adjustment Board.

Mansoor, I. (1992). Indicators of program quality: An ESL programming perspective. In Program and provider perspectives on developing indicators of program quality for adult education programs (pp. 8-39). Washington, DC: Pelavin Associates. (ERIC Document Reproduction Service No. ED 361 591)

National ELICOS Accreditation Scheme. (1995). Guidelines for accreditation as an ELICOS institution. Pyrmont, NSW: Author.

Selman, M. (1991). Adult ESL program evaluation guide. Victoria, BC: Ministry of Advanced Education, Training and Technology.

TESOL. (1995). Statement of core standards for language and professional programs. Washington, DC: Author.

TESOL. (1997). Draft accreditation standards for intensive English programs. Available: http://www.tesol.edu.html.

Wrigley, H.S., \& Ewen, D.T. (1995). A national language policy for ESL: Issues in ESL Education 2. (ERIC Document Reproduction Service No. ED 379 969)

Wrigley, H.S., \& Guth, G.J. (1992). Bringing literacy to life: Issues and options in adult ESL literacy. San Mateo, CA: Aguirre International.

Wrigley, H.S., Spruck, H., et al. (1993). Sparks of excellence: Program realities and promising practices in adult ESL. A report on an investigation of English as a second language service for adults. Washington, DC: Southport Institute for Policy Analysis. (ERIC Document Reproduction Service No. ED 373 586) 